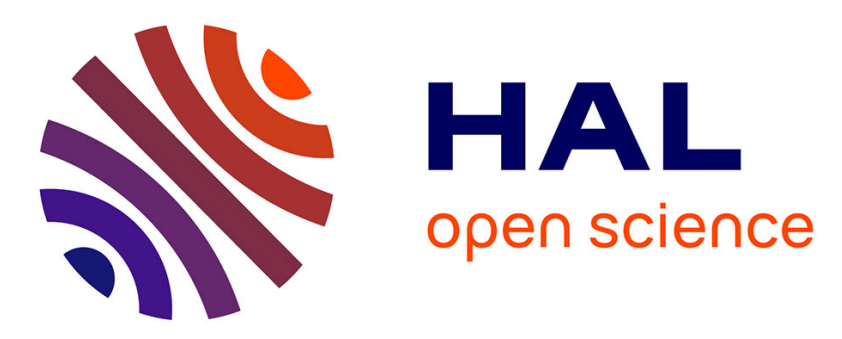

\title{
AXIN deficiency in human and mouse hepatocytes induces hepatocellular carcinoma in the absence of $\beta$-catenin activation
}

Shirley Abitbol, Rajae Dahmani, Cédric Coulouarn, Bruno Ragazzon, Bernhard Mlecnik, Nadia Senni, Mathilde Savall, Pascale Bossard, Pierre Sohier, Valerie Drouet, et al.

\section{To cite this version:}

Shirley Abitbol, Rajae Dahmani, Cédric Coulouarn, Bruno Ragazzon, Bernhard Mlecnik, et al.. AXIN deficiency in human and mouse hepatocytes induces hepatocellular carcinoma in the absence of $\beta$ catenin activation. Journal of Hepatology, 2018, 68 (6), pp.1203-1213. 10.1016/j.jhep.2017.12.018 . hal-01807225v2

\section{HAL Id: hal-01807225}

https://hal-univ-rennes1.archives-ouvertes.fr/hal-01807225v2

Submitted on 10 Jan 2022

HAL is a multi-disciplinary open access archive for the deposit and dissemination of scientific research documents, whether they are published or not. The documents may come from teaching and research institutions in France or abroad, or from public or private research centers.
L'archive ouverte pluridisciplinaire HAL, est destinée au dépôt et à la diffusion de documents scientifiques de niveau recherche, publiés ou non, émanant des établissements d'enseignement et de recherche français ou étrangers, des laboratoires publics ou privés. 
archives-ouvertes

\section{AXIN deficiency in human and mouse hepatocytes induces hepatocellular carcinoma in the absence of $\beta$-catenin activation}

Shirley Abitbol, Rajae Dahmani, Cédric Coulouarn, Bruno Ragazzon, Bernhard Mlecnik, Nadia Senni, Mathilde Savall, Pascale Bossard, Pierre Sohier, Valerie Drouet, et al.

\section{To cite this version:}

Shirley Abitbol, Rajae Dahmani, Cédric Coulouarn, Bruno Ragazzon, Bernhard Mlecnik, et al.. AXIN deficiency in human and mouse hepatocytes induces hepatocellular carcinoma in the absence of $\beta$-catenin activation. Journal of Hepatology, Elsevier, 2018, 68 (6), pp.1203-1213. 10.1016/j.jhep.2017.12.018 . hal-01808100

HAL Id: hal-01808100

https://hal-univ-rennes1.archives-ouvertes.fr/hal-01808100

Submitted on 4 Oct 2018

HAL is a multi-disciplinary open access archive for the deposit and dissemination of scientific research documents, whether they are published or not. The documents may come from teaching and research institutions in France or abroad, or from public or private research centers.
L'archive ouverte pluridisciplinaire HAL, est destinée au dépôt et à la diffusion de documents scientifiques de niveau recherche, publiés ou non, émanant des établissements d'enseignement et de recherche français ou étrangers, des laboratoires publics ou privés. 


\section{AXIN1 DEFICIENCY IN HUMAN AND MOUSE HEPATOCYTES INDUCES HEPATOCELLULAR CARCINOMA IN THE ABSENCE OF B-CATENIN ACTIVATION}

Shirley Abitbol ${ }_{1,2,3,4}$, Rajae Dahmani ${ }_{1,2,3,4}$, Cédric Coulouarn5, Bruno Ragazzon 1,2,3, Bernhard Mlecnik6, Nadia Senni1,2,3,4, Mathilde Savall 1,2,3,4, Pascale Bossard1,2,3,4, Pierre Sohier1,2,3,4,7, Valerie Drouet1,2,3,4, Emilie Tournier1,2,3, Florent Dumont1,2,3, Romain Sanson1,2,3,4,7, Julien Calderaro,8, Jessica Zucman-Rossi,8, Mireille VasseurCognet10, Pierre-Alexandre Just1,2,3,4,7, Benoît Terris1,2,3,4,7, Christine Perret1,2,3,4**, Hélène Gilgenkrantz1,2,3,4, $9^{* *}$

1INSERM, U1016, Institut Cochin, F-75014 Paris, France.

2CNRS, UMR8104, F-75014 Paris, France.

3Université Paris Descartes, F-75014 Paris, France.

4Equipe labellisée LNCC.

5INSERM, INRA, Univ Rennes 1, Univ Bretagne Loire, Nutrition Metabolisms and Cancer (NuMeCan), F-35033, Rennes, France.

6Inovarion, 75013 Paris, France.

7APHP, Hôpitaux Universitaires Paris Centre, Hôpital Cochin, Pathology Department, 75014 Paris, France

8 Inserm, UMR-1162, Functional Genomics of Solid Tumors, Université Paris Descartes, Université Paris Diderot, Université Paris 13

${ }_{9}$ Centre de Recherche sur I.Inflammation- Inserm UMR 1149- Université Paris Diderot, Paris France

10 UMR IRD 242, UPEC, CNRS 7618, UPMC 113, INRA 1392, Sorbonne Universités Paris and Institut d'Ecologie et des Sciences de l'Environnement de Paris, Bondy, France

*These authors contributed equally to this study

**Corresponding authors: Institut Cochin, INSERM U 1016, CNRS UMR8104, Université Paris Descartes, 24 rue du Faubourg Saint-Jacques, 75014 PARIS, FRANCE. Fax: 33144412421 ;

helene.gilgenkrantz@inserm.fr; Phone: 33157277530

christine.perret@inserm.fr; Phone: 33144412564 
Running title: Axin1-mutated HCCs occur independently of $\beta$-catenin pathway activation

Electronic word count: 6836

Number of figures : 7

Conflict of interest: The authors declare not to have any competing financial interests in relation to the work described.

Financial support :This study was supported by the LNCC (Ligue Nationale Contre le Cancer) and Association Française pour l'Etude du Foie (AFEF)

Authors Contributions: $\mathrm{SA}, \mathrm{RD}, \mathrm{NS}, \mathrm{PB}, \mathrm{MS}, \mathrm{RS}, \mathrm{VD}, \mathrm{RS}$ : experiments and procedures; ET: generation of KO mice; CP, HG: concept and design; CC, BR, BM, FD, PS: microarrays and statistical analysis, PAJ, BT: pathologists, tumor analysis; JZR, JC : Human AXIN1-mutated tumors; CP, HG: writing of article.

Keywords: Liver, cancer, tumor signature, mouse model 


\section{Lay Summary:}

Liver cancer has a poor prognosis. Defining the molecular pathways involved is detrimental to develop new therapeutic approaches. The $\mathrm{Wnt} / \beta$-catenin pathway is the most frequently deregulated pathway in hepatocellular carcinoma (HCC). Mutations of $A X I N 1$, a member of this pathway, represent about $10 \%$ of $\mathrm{HCC}$ mutations. Using both human HCC collections and engineered mouse models of liver cancers with AXIN1 mutation or deletion, we defined a common signature of liver tumors mutated for AXIN1 and demonstrate that these tumors occur independently of the activation of the $\mathrm{Wnt} / \beta$-catenin pathway. 


\begin{abstract}
Background and aims: The $\mathrm{Wnt} / \beta$-catenin pathway is the most frequently deregulated pathway in hepatocellular carcinoma (HCC). Inactivating mutations of the gene encoding $A X I N 1$, a known negative regulator of the $W n t / \beta$-catenin signaling pathway, are observed in about $10 \%$ of HCCs. Whole-genome studies usually place HCC with AXIN1 mutations and CTNNB1 mutations in the group of tumors with Wnt/ $\beta$-catenin activated program. However, it has been shown that HCCs with activating CTNNB1 mutations form a group of HCCs, with a different histology, prognosis and genomic signature compared to those with inactivating biallelic AXIN1 mutations. We aimed at understanding the relationship between CTNNB1 mutations, AXIN1 mutations and the activation level of the $\mathrm{Wnt} / \beta$-catenin program.
\end{abstract}

Methods: We evaluated two independent human HCC datasets for the expression of a 23- $\beta$-catenin target genes program. We modeled Axin1 loss of function tumorigenesis in two engineered mouse models and performed gene expression profiling.

Results: Based on gene expression, we defined three levels of $\beta$-catenin program activation: strong, weak or no activation. While more than $80 \%$ CTNNB1-mutated tumors were found in the strong or in the weak activation program, most of the AXIN1-mutated tumors (>70\%) were found in the subgroup with no activation. We validated this result by demonstrating that mice with a hepatocyte specific AXIN1 deletion developed HCC in the absence of $\beta$-catenin induction. We defined a 329gene signature common in human and mouse AXIN1 mutated HCC that is highly enriched in Notch and YAP oncogenic signatures. 
Conclusions: AXIN1-mutated HCCs occur independently of the Wnt/ $\beta$-catenin pathway and involve Notch and YAP pathways. These pathways constitute potential interesting targets for the treatment of HCC due to AXIN1 mutations.

Electronic word count of the abstract: 268 


\section{Introduction}

Hepatocellular carcinoma (HCC) is the third most frequent cause of cancer death worldwide. HCC is a highly heterogeneous disease, occurring in a context of chronic liver injury and inflammation leading to cirrhosis (1). Recent genomic studies have provided an accurate description of the landscape of genetic changes underlying HCC and identified the molecular pathways most frequently altered, among which the $\mathrm{Wnt} / \beta$-catenin pathway is prominent (2-6). This conserved signaling pathway governs embryonic development, homeostasis and liver zonation in adults. In the absence of Wnt stimulation, the cytosolic concentration of $\beta$-catenin remains low due to a multiprotein destruction complex including CK $1 \alpha$, GSK3 $\beta$, YAP/TAZ, APC and AXIN1, which promotes the phosphorylation of $\beta$-catenin. Once phosphorylated, $\beta$-catenin is degraded by the proteasome. In response to Wnt stimulation, the destruction complex is recruited to the membrane. This stabilizes $\beta$ catenin, which then enters the nucleus and activates the expression of Wnt target genes, mostly through the lymphoid enhancer-binding factor 1 (LEF-1) and T-cell transcription factor (TCF).

Among mutations in the members of this $\mathrm{Wnt} / \beta$-catenin pathway, somatic activating mutations in CTNNB1 gene coding for $\beta$-catenin are identified in $11-37 \%$ of HCC (2) and inactivating mutations of $A X I N 1$ and $A P C$ are found in $5-15 \%$ and $1-2 \%$ of $H C C$ respectively. AXIN1 is a scaffolding protein initially identified as a negative regulator of the canonical Wnt pathway and the rate-limiting factor of the destruction complex (7). It was thus anticipated that a loss of $A X I N 1$ function in the liver would lead to aberrant activation of the $\beta$-catenin pathway, as reported for inactivating $A p c$ mutations in mice (8). Consistent with this prediction, Satoh et al. showed that HCC 
cell lines with AXIN1 mutations displayed an activation of $\mathrm{Wnt} / \beta$-catenin signaling, although this effect was weak (9). We then described that human HCCs with inactivating AXIN1 mutations expressed a genetic program different from that in CTNNB1-mutated (10). In addition, HCC with AXIN1 or CTNNB1 mutations belong to two different major subclasses of HCC: CTNNB1 mutations were associated to the non proliferative class and G5-G6 subgroups with a better prognosis, while AXIN1 loss of function mutations were associated with the proliferative class and G1-G2 subgroups with an enrichment of signals relating to cell cycle and a more aggressive phenotype (11). The conditional loss of Axin1 in mouse hepatocytes was found to lead to the transient up-regulation of very few $\beta$-catenin target genes (12) and to induce the development of HCC, comforting the tumor suppressor role of Axin1. However, no molecular characterization of these tumors was carried out (12). These conflicting observations call into question the relationship between CTNNB1 mutation types, AXIN1 mutation types and intensity of $\beta$-catenin program activation. The aim of this work was to study the spectrum of CTNNB1 and AXIN1 mutations in a large series of human $\mathrm{HCC}$ in correlation with the activation of the $\beta$-catenin program and to define an AXIN1-mutated tumor signature based both on mouse HCC experimentally obtained after Axin1 deletion in hepatocytes and AXIN1-mutated human HCC.

\section{Materials and Methods}

\section{Mouse models}

The Axin1-targeting construct was generated from PCR (Polymerase Chain Reaction) products amplified from the DNA of 129/SV ES cells with the Pfx polymerase (Life Technologies). A schematic diagram of the Axin ${ }^{\mathrm{fl} / \mathrm{fl}}$ alleles and 
procedure of mice obtention is provided in Figure 1A (see suppl data). All animal procedures were carried out in accordance with French government regulations, with the approval of the Paris-Descartes Ethics Committee for animal experimentation, under protocol CEEA34.CP.077.12. Mice were housed in SPF (specific pathogen free) conditions under $12 \mathrm{~h}$ light/dark cycle with free access to water and standard mouse chow. Wild type (WT) control mice are monogenic Axin ${ }^{f / f f}$ cohoused littermates that do no express Cre recombinase. APC KO male mice (8) at 6-8 weeks old were used as controls of beta-catenin pathway activation. For more details see Supplemental data. Gender and number of animals are indicated in the figure legends.

\section{Immunoblotting and immunohistochemistry}

Analysis of cell protein expression by immunoblotting and detection of protein expression by immunofluorescence were performed as described in Supplementary material and methods.

Analysis of gene expression by reverse transcription-polymerase chain reaction

RNA extraction retrotranscription and quantitative PCR were performed as indicated in supplementary material and methods. Primer sequences are provided in Suppl. Table 8.

\section{Mouse RNA profiling and Human Gene expression analysis}

We used freshly frozen samples from eight tumors from five KO LivEmb male 16 months old mice $(T)$, the corresponding adjacent non-tumoral liver samples (NT) and 3 control livers of male mice of the same age. For Affymetrix arrays analysis and Human Gene expression analysis, see supplementary material and methods and supplementary CTAT Table. Microarraay raw data are deposited at Gene Expression 
Omnibus (GEO accession number GSE 107374).

\section{Statistical analysis and data mining}

Student's $t$ test and paired $t$ tests were used for comparisons of variables, as indicated. Ingenuity pathway analysis (IPA) software (Mountain View, CA, USA) was used to examine the functional association between differentially expressed genes and to identify the molecular functions and gene networks displaying the most significant alterations, with the IPA scoring system. Gene set enrichment analysis (GSEA) was performed with the Java tool application available at the Broad Institute (Cambridge, MA, USA), using the default settings. Mann-Withney $U$ test and Fisher's exact test analysis were done using the R statistical software. All P-values were twosided and considered significant with $p<0.05$. Hierarchical cluster were performed using the Genesis clustering software.

\section{Results}

CTNNB1 and AXIN1 mutated HCCs reveal different patterns of $\beta$-catenin activity

We studied 454 human HCC belonging to two independent human public datasets, GSE62232 (4) (81 samples) and TCGA-LIHC (373 samples) (supplementary CTAT Table), for which, both the genetic status for CTNNB1 and AXIN1, and the RNA expression profile, were available (Suppl Table 1AB). Expression of the CTNNB1 program was explored using a 23 genes signature including 9 canonical and 14 liver specific CTNNB1 target genes (13-17). Among all the tumors, 132 were mutated for CTNNB1, 40 for AXIN1 including 5 mutated for both genes (Suppl Table 1, Figure 1A-B). Hierarchical clustering analysis based on the expression of the 23-gene signature in GSE62232 and TCGA-LIHC datasets identified three clusters 
characterized by a strong, weak and lack of expression of the CTNNB1 program (Figure $1 \mathrm{~A}$ and Figure 1B). As expected, the vast majority (79/86) of tumors expressing a strong CTNNB1 program were CTNNB1-mutated (Figure 1C). Furthermore, out of the seven non-mutated-CTNNB1 HCCs in the TCGA-LIHC dataset, three were mutated for APC combined with a loss of heterozygosity (LOH), revealing an $A P C$ loss of function. However, no HCC with only AXIN1 mutations were recorded in this first cluster with a "strong CTNNB1 program" (Figure 1A-B and Suppl Table 2). Two HCC with AXIN1 mutation in this cluster were also mutated for CTNNB1. By contrast, in the second cluster with a "weak CTNNB1 program", $56.6 \%$ of HCC were mutated in CTNNB1 (30/53) and 15\% in AXIN1 (8/53). Interestingly, CTNNB1 mutations were enriched in the hot spot S45 located in CTNNB1 exon 3 and in the recently described mutations located in exon7 and 8 (K335, W383) $(2,18$, COSMIC database)(Suppl Fig.1). Finally, in the third cluster in which no $\beta$-catenin activity was found, mutations in CTNNB1 or AXIN1 or APC occurred in less than $20 \%$ of HCCs. All the APC mutations in the TCGA-LIHC dataset were mono-allelic and $54 \%$ of CTNNB1 mutations were not canonical with unknown consequences (Suppl Table 2). In addition, $38 \%$ of the CTNNB1 mutations were located in exon7 and 8 (K335, W383, R386, N387) whose functions are still not understood and described as weak mutations (2). In contrast, all the AXIN1-mutated HCC of the third cluster in the TCGA-LIHC are loss of function mutations (22/23 with a stop codon or splice site mutation) combined with LOH. AXIN1 mutations in GSE62232 are also loss of function mutations $(4,19)$. Most importantly, with the exclusion of HCC mutated both for CTNNB1 and AXIN1, the distribution of AXIN1 mutations revealed that $80 \%$ (28/35) of AXIN1-mutated HCC belong to the third group with no or weak $\beta$-catenin program activation (Figure 1C). 
Human AXIN1-mutated human HCC with available histological virtual slides from the TCGA bank were analysed by two pathologists. Among these $25 \mathrm{HCC}, 4$ were poorly differentiated while 15 were moderately differentiated. Two had focal steatosis in about $10 \%$ of tumor cells. In contrast, as already published (20), CTNNB1-mutated HCC exhibited a well-differentiated pattern with low-grade cellular atypia.

Altogether these results revealed that human HCCs with AXIN1 and CTNNB1 mutations do not show a similar $\beta$-catenin activity. AXIN1-mutated HCCs split in two distinct groups, the first that includes only few AXIN1-mutated tumors has a weak $\beta$ catenin activity, and the second that includes most of the AXIN1-mutated tumors, shows no activation of the $\mathrm{Wnt} / \beta$-catenin signaling.

\section{Axin1 deletion in the liver induces HCC without Wnt/ $\beta$-catenin pathway activation}

We then modeled the Axin1 loss of function in the liver by generating mice bearing a specific deletion of Axin1 in the hepatocytes to better understand results obtained using human $\mathrm{HCC}$ samples. We first generated an Axin1 conditional liver knockout mouse model, in which exons 4 and 5 , encoding part of the GSK3 $\beta$ and $\beta$ catenin binding site, were flanked by loxP sites (Figure 2A,B). Homozygous Axin $1^{\text {lox/lox }}$ mice were crossed with two different mouse strains to generate Axin1 deletion in the embryonic liver (KO LivEmb) or in the adult liver upon tamoxifen injection (KO LivAd) (Figure 2C). Liver tumors with no Axin1 expression (Suppl. Fig. 2A) were detected after eight to nine months in $30 \%$ of mutant mice by ultrasonography. By the age of 12 months, mutant mice developed HCC with $40 \%$ penetrance with a similar proportion in males and females. In contrast, none of the 
control monogenic mice developed HCC. About $15 \%$ of the mice developed multifocal tumors in both models, and one mouse out of 42 mice with tumors had lung metastases (Figure 3A and Suppl Fig 2B). The morphological features of these HCC were heterogeneous but the majority showed moderate differentiation (Suppl. Fig. 2C). Focal or extensive steatosis was observed in $85 \%$ tumors (Figure $3 \mathrm{~A}$ and Suppl. Fig. 2C). Tumors were Cyclin D1 positive (Suppl Fig. 2D). A marker of DNA double-strand breaks, $\gamma H 2 A X$, was found induced in the tumor samples compared to the adjacent non-tumor samples (Suppl. Fig. 2E). No nuclear or cytoplasmic $\beta$ catenin staining, nor immunostaining for glutamine synthetase (GS), a surrogate marker of $\mathrm{HCC}$ with $\beta$-catenin activation, was observed in tumors (Figure 3B). The expression of $\beta$-catenin target genes was not up-regulated in tumor compared to the adjacent non-tumor tissues, as shown by RT-qPCR (Figure 3C). Accordingly, Axin2 protein was not induced in tumor compared to non-tumor samples (Figure 3D). Equivalent results were obtained in both KO LivEmb and KO LivAd mouse models. Finally, among genes encoding known components of the $\mathrm{Wnt} / \mathrm{\beta}$-catenin signaling pathway (Fzd7, DKK3, TCF4, TCF1, LRP6, Dvl1), none was found to be induced in tumors (Suppl. Fig. 2F).

\section{Deletion of Axin1 in embryonic or adult liver does not lead to Wnt/B-catenin pathway activation in pre-tumoral livers}

Mutant pre-tumoral livers were analyzed four months after birth (KO LivEmb) or 2 months after tamoxifen injection (KO LivAd mice). The mutant mouse livers had a normal histological appearance in both models, with a conserved lobular architecture and no evidence of hepatocyte injury (data not shown). An analysis of the $\beta$-catenin subcellular distribution revealed that it was present at the membrane 
but did not accumulate in the cytoplasm or nucleus, contrary to livers in which a specific Apc deletion has been targeted in hepatocytes (KO APC) (8) (Figure 4A). GS was limited to a few layers of hepatocytes around the central vein, as in control livers, whereas it was found throughout the entire lobule in Apc mutant mice (Figure 4A). Consistent with these data, RT-qPCR showed an absence of modulation of $\beta$-catenin transcriptional targets expression in the two models, contrasting with the strong dysregulation of these targets in Apc mutant mice livers (Figure 4B). No induction of $\beta$-catenin positive target genes (Axin2, Sp5, Lect2, Cyp2E1 and Glul) (Suppl. Fig. 3 A,B) nor induction of Axin2 protein (Suppl. Fig. 3 C, D) was observed at earlier time points after tamoxifen injection. We used the luciferase-based reporter system TOP/FOP to investigate $\beta$-catenin transcriptional activity in Axin 1 or Apc inactivated mouse primary hepatocytes and in Huh7 human HCC cell line in which we have inactivated AXIN1 using siRNA (Suppl Fig 4 A-D). We observed strong TCFdependent transcriptional activity in primary hepatocytes of KO Apc mice (Suppl. Fig. 4A). In contrast, we only observed a weak activity in Axin1-deleted murine hepatocytes or in Huh7 human cell line transfected with a siRNA directed against AXIN1. This basal transcriptional activity was confirmed by RT-PCR of $\beta$-catenin target genes (Suppl. Fig. 4B). To check the specificity of this very low $\beta$-catenindependent transcription, we added a siRNA directed against $\beta$-catenin and observed a significant decrease in the $\beta$-catenin reporter activity in all cell types (Suppl. Fig. 4A, C). The inhibition of $A P C$ in Huh7 inactivated for $A X I N 1$ restored a strong $\beta$ catenin activation (Suppl. Fig. 4C).

Altogether, the results showed that Axin1 loss of function in hepatocytes in vivo, did not lead to activation of the $\beta$-catenin signaling. However, mouse Axin1-KO primary hepatocytes revealed a weak activation of a $\beta$-catenin program, far less than 
the one obtained using Apc-KO primary hepatocytes. Similar results were obtained when the HuH7 hepatoma cells were inactivated for AXIN1.

\section{Mouse HCCs with Axin1 deletion cluster in the G1-G2, S1 and proliferative human HCC class with progenitor and poor prognosis signatures}

We performed genomic profiling of 8 tumors (T) derived from $5 \mathrm{KO}$ LivEmb male mice and their adjacent non-tumoral (NT) samples using microarrays. Three monogenic Axin $1^{\text {lox/lox }}$ mice of the same age were also included as control livers. The analysis identified 657 genes as upregulated and 447 genes as downregulated in the tumors compared to the non-tumoral adjacent tissue (fold-change $>1.5$ and $P$ value<0.05). Gene ontology analysis of biological functions associated with the differentially expressed genes revealed a significant upregulation of genes involved in mitosis, cytokinesis and cell division (Suppl. Table 3), known markers of proliferative HCCs. Interestingly, GSEA revealed an enrichment in gene signatures specific HCC subclasses previously associated with a proliferative and more invasive phenotype together with a worse outcome, e.g. G1-2-3 described by Boyault et al. (11), S1 described by Hosdida (21), and the proliferation subclass described by Chiang et al. (22) (Suppl. Table 4, Figure 5A). In addition, we found a significant enrichment $(p<0.05)$ in tumor signatures associated with invasion, stemness and poor prognosis features (Figure 5A and Suppl. Table 5). Accordingly, fetal genes, such as Afp, Tff3, Spink1/3 and Cbr3 were among the genes most strongly induced in tumors (Figure 5B). Moreover, ANXA2 and pERK known to be associated with poor prognosis in $\operatorname{HCC}(23,24)$ were also found induced in all Axin1-deficient liver tumors in both models (Figure 5C). 
Taken together, our results demonstrate that the loss of Axin1 in mouse liver induces $\mathrm{HCC}$ independently of $\mathrm{Wnt} / \beta$-catenin pathway activation and that the genomic profiles of these tumors recapitulate those of "proliferative" subclass of human HCC with a poor clinical outcome.

\section{Identification of oncogenic pathways in Axin1-mutated HCC}

Since our results suggest that Axin1 loss in mouse liver requires oncogenic events different from $\beta$-catenin pathway, we looked at AXIN1 known partners such as Notch $(25,26)$, YAP/TAZ (27), TGF $\beta$ (28) or JNK (29). Unsupervised GSEA revealed a significant enrichment of Notch, YAP/TAZ and TGF- $\beta$ signatures in the profile of mouse tumors (vs. NT) (Suppl. Tables 4 and 5). Notably, we found a significant enrichment of a 384-gene Notch signature defined in mouse tumors expressing the Notch intracellular domain and found to be enriched in human tumors of the proliferative class (30) (Figure 6A). We observed a significant overlap in the gene expression profiles of Axin1 and NICD mouse tumors with 143 genes (37\%, 109 upregulated, 35 downregulated) commonly dysregulated (Suppl. Table 6). We confirmed the induction of several common genes by RT-qPCR on a different set of seven KO LivAd tumors (Figure 6B). Canonical Notch target genes such as Hey1, Hes1, Heyl and Notch1 were also found significantly induced, although at a lower level (Figure 6B). Osteopontin (Spp1), a Notch target predictive of a poor prognosis of HCC (31), was found to be induced in 5/7 KO LivAd tumors and 4/6 KO LivEmb tumors at protein levels (Figure 6C). We also observed in most of the tumor samples in both models, although heterogeneously, a nuclear accumulation of Sexdetermining region Y-box9 (Sox9), a marker of liver progenitor cells expressed during embryogenesis that is also a Notch target gene (Figure 6D). 
GSEA indicated an enrichment of a YAP signature in tumor samples (32) (Figure 6E, Suppl.Table 5) and the induction of YAP target genes expression was confirmed by RT-qPCR on KO LivAd tumors (Figure 6F). Protein-based analyses revealed the heterogeneous induction of YAP and TAZ production in some, but not all tumors with Axin1 deletion (Figure 6G). Nuclear extracts of tumors induced for this pathway showed a nuclear YAP/TAZ tumoral enrichment (Figure 6G). However, the tumoral heterogeneity suggested that additional oncogenic pathways might be involved. We indeed observed TGF- $\beta$ expression in half of the tumors as well as cjun phosphorylation, as a marker of JNK activation (data not shown).

\section{A common signature in human and mouse AXIN1 mutated HCC highlights the activation of Notch and YAP pathways}

We evaluated the relevance of mouse tumors with Axin1 deletion to human carcinogenesis. For that purpose, we used data of TCGA-LIHC consortium in which all the AXIN1-mutated HCCs have a $\mathrm{LOH}$, and are supposed to be loss of function mutations. HCC bearing both AXIN1 and CTNNB1 mutations were excluded. We established a list of genes that were significant differentially expressed (fold change $>2 ; \mathrm{p}<0,05)$ in AXIN1-mutated human HCC compared to control liver tissue and performed the same analysis for mouse HCCs. The final signature, built upon the overlapping human vs mouse orthologs consists of 329 genes with 198 genes upregulated in tumors compared to normal livers and 131 genes down-regulated (Suppl. Table 7). Genes involved in cell cycle regulation were significantly upregulated in tumors, including CCNB2, CCNB1, DNASE1, CDK1, CDC20, BUB1, TOP2a, AURKA, CDKN2C. Similarly, genes associated with a poor prognosis, recurrence or invasion such as ANXA2 (23), CENPF (33) NEK2 (34) or RACGAP1 
whose interactome involves genes with mitotic roles of the polo-like kinases such as $P R C 1, A U R K B, E C T 2$ or PAK1 (35) were included as well in this signature. Genes involved in farnesoid $\mathrm{X}$ receptor family members, primary bile acid and sterol biosynthesis were down-regulated. Non-supervised hierarchical clustering showed that TCGA-LIHC human tumors and mouse AXIN1-mutated HCC clustered together on this signature (Suppl. Fig. 5). Interestingly, the 329-gene AXIN1 signature showed a highly significant enrichment of the oncogenic Notch signature based on HCC mouse models (30) and the YAP oncogenic signature (32) as seen in Figure 7. Noteworthy, HMMR, BIRC5, CYR61 (YAP pathway), CDKN3, TSPAN8 and SOX9 (Notch pathway) were significantly induced in AXIN1 mutated TCGA-LIHC human HCC.

Finally, we performed immunohistochemistry on 8 human AXIN1-mutated HCC from GSE62232 cohort, among which 2 were well differentiated while the 6 others were poorly to moderately differentiated (Suppl. Fig 6 A, B). We observed NOTCH2 staining in 6 of them (Suppl Fig 6 C, D) and YAP nuclear staining in 4 of them (Suppl. Fig 6 E, F). Altogether, these data confirm the induction of YAP and Notch pathways in a majority of AXIN1- mutated human HCC. 


\section{DISCUSSION}

In the present study, we showed that the majority of HCC with AXIN1 mutations develop in the absence of the $\mathrm{Wnt} / \beta$-catenin pathway activation. To date, AXIN1-mutated HCC have been poorly studied and data are inconsistent. Previous studies, including the most recent studies based on whole-exome or whole-genome analyses, recurrently placed HCC with AXIN1 mutations and those with CTNNB1 mutations in the same group $(3,4,36)$. This classification was based on the notion that CTNNB1 and $A X I N 1$ are both involved in the Wnt/ $\beta$-catenin pathway, and on previous reports showing an activation of $\beta$-catenin signaling, although weak, in human HCC cell lines bearing inactivating AXIN1 mutations (9). In the present study, we have used a canonical and liver-specific $\beta$-catenin signature to analyze the level of $\beta$-catenin activity of CTNNB1- and AXIN1-mutated HCC in two independent data sets that include 454 human HCC. We defined three different clusters displaying, strong, weak, or no $\beta$-catenin activity. Overall, our data are consistent with a recent study showing that CTNNB1-mutated HCC exhibit heterogenous levels of $\beta$-catenin activity (2). The differences are likely due to the fact that the study by Rebouissou et al, was based on only two $\beta$-catenin target genes while our analysis included 23 target genes. The most notable difference is our description of a subgroup of CTNNB1- or APC-mutated HCC without any $\beta$-catenin activity. Among these HCC, a lot of mutations are likely to be non-functional such as mono-allelic APC mutations or atypical CTNNB1 mutations. It is of interest to note that in the two groups of weak and lack of $\beta$-catenin activity, there is an enrichment in the hot spot S45 CTNNB1 mutations and in the new CTNNB1 mutations described in Arm 5 and 6 domains (K335I, W383, N387). We observed an enrichment in K335I mutation in the "weak CTNNB1 program" cluster and an enrichment in N387K in the "no CTNNB1 program" cluster, suggesting that the N387K are likely to be not functional. The reason why 
S45 CTNNB1 mutations could lead to either weak or no $\beta$-catenin activity (at almost the same incidence) remains to be investigated. Likewise, the reason why some AXIN1-mutated HCC showed a weak $\beta$-catenin activity, while most of them revealed no $\beta$-catenin activity is also intriguing. There is no hotspot mutation in AXIN1 and we observed no correlation between the genotype of AXIN1 mutation and the phenotype of $\beta$-catenin activity. In addition, the reason why a faint activation of a $\beta$-catenin program has been described in AXIN1-mutated hepatoma cell lines $(9,10)$ that we confirmed after si-RNA inactivation of AXIN1 in (Supplementary CTAT Table), and also in Axin1-deleted mouse primary hepatocytes, is likewise intriguing. However, our main finding is the demonstration that $80 \%$ of the AXIN1-mutated HCC did not display any activation of the $\beta$-catenin signaling.

Our modeling of Axin1 inactivation in mouse liver confirmed that $\mathrm{HCC}$ that developed following the deletion of Axin1 in the hepatocytes are not activated for the $\beta$-catenin signaling. The characterization of the mouse tumors showed that Axin1mutated HCC clustered with the previously described S1 (21) and G1-G3 (11) human subgroups of HCC, which display chromosomal instability and a transcriptional signature associated with poor prognosis, invasiveness and stem cell features, underlining the relevance of the mouse model.

In addition, we observed no induction of $\beta$-catenin target genes in the liver of Axin1 mouse models at earlier time points, excluding even transient activation of the $\beta$-catenin pathway. We also found no expression of different $\mathrm{Wnt} / \beta$-catenin partners, already described in HCC bearing an activation of the $\beta$-catenin signaling without CTNNB1 mutations (37). The lack of up-regulation in Axin2 expression is not consistent with the hypothesis of Axin2-mediated compensation. Our data differ from those of Feng et al., reporting that Axin1 deletion in mice results in the transient 
induction of some $\beta$-catenin target genes (12). This discrepancy may be due to the mouse models used, which differed in the invalidation construct and in the Cre recombinase used, which expression was not restricted to the liver in Feng's study. Thus, although AXIN1 has been described as the limiting scaffolding protein of the $\beta$ catenin degradation complex (7), its role is likely more complex than initially described.

In our mouse model, HCCs arose after a significant latency period and in only 40\% of Axin1 mutant mice, indicating that Axin1 loss of function alone is only mildly oncogenic. These findings, together with the heterogeneity of the tumors, indicate that although Axin1 is a tumor suppressor, its loss in the liver requires additional oncogenic events that may differ between tumors. This suggests that Axin1 is a not powerful tumor suppressor gene in the mouse and suggests that in human, AXIN1 mutations are unlikely to be potent drivers that initiate HCC development.

We identified a common signature based on both mouse and human datasets. Oncogenic Notch and Yap pathways, which dialog in the liver and in HCC (38), were found highly enriched in this signature. It has been recently demonstrated in drosophila that Axin1 loss induces activation of the Notch pathway (25). Notch activation in human $\mathrm{HCC}$ is associated with poorer tumor cell differentiation, venous invasion, an advanced tumor stage and shorter overall survival $(39,40)$. YAP/TAZ is known to form a critical positive feedback loop with Notch signaling to promote HCC formation with bad prognosis $(38,41)$. In addition, Hmmr for hyaluronan-mediated motility receptor (also called Rhamm), a YAP target gene that promotes microtubule instability, induces ERK activation and is strongly expressed in aggressive human cancers $(42,43)$, was also found induced in both human and mouse tumors with AXIN1 mutations. Our observation of YAP activated HCC in the absence of AXIN1 
can be explained by the fact that AXIN1 directly associates with endogeneous YAP and TAZ and that knockdown of Axin1 is known to cause YAP/TAZ stabilization and nuclear accumulation in vitro (26). Moreover, the recently uncovered inhibitory role of $\beta$-catenin on YAP and Notch activities for the initiation of HCC (41) could explain why Notch and $\beta$-catenin pathways, inducing contradictory signals, are not activated simultaneously in HCC.

In conclusion, although genomic studies describing the mutational landscape of HCC have until now classified tumors with either activating CTNNB1 or inactivating AXIN1 mutations as belonging to the same "Wnt/ $\beta$-catenin" group, those should clearly be considered to belong to different groups from now on. Notch and YAP signaling are induced in both human AXIN1-mutated HCC and mouse HCC resulting from liver Axin1 deletion. Small compounds inhibiting YAP-driven hepatocarcinogenesis have shown encouraging results and may provide a novel approach for the treatment of AXIN1-mutated HCC with YAP/Notch pathway induction (44). In this context, the mouse model we have developed constitutes an ideal tool for evaluating new treatments preventing the sequence of tumor development at various stages of progression. 


\section{References}

1. El-Serag HB, Rudolph KL. Hepatocellular carcinoma: epidemiology and molecular carcinogenesis. Gastroenterology 2007 ;132(7):2557-2576.

2. Rebouissou S, Franconi A, Calderaro J, Letouze E, Imbeaud S, Pilati C, et al. Genotype-phenotype correlation of CTNNB1 mutations reveals different $\beta$-catenin activity associated with liver tumor progression. Hepatology 2016 ;64(6):2047-2061.

3. Zucman-Rossi J, Villanueva A, Nault JC, Llovet JM. Genetic Landscape and Biomarkers of Hepatocellular Carcinoma. Gastroenterology 2015;149(5):1226-1239 e4.

4. Schulze K, Imbeaud S, Letouze E, Alexandrov LB, Calderaro J, Rebouissou S, et al. Exome sequencing of hepatocellular carcinomas identifies new mutational signatures and potential therapeutic targets. Nat Genet 2015;47(5):505-511.

5. Fujimoto A, Furuta M, Totoki Y, Tsunoda T, Kato M, Shiraishi Y, et al. Wholegenome mutational landscape and characterization of noncoding and structural mutations in liver cancer. Nat Genet 2016;48(5):500-509.

6. Calderaro J, Couchy G, Imbeaud S, Amaddeo G, Letouzé E, Blanc JF, et al. Histological Subtypes of Hepatocellular Carcinoma Are Related To Gene Mutations and Molecular Tumour Classification. J Hepatol. 2017; 67(4):727-738.

7. Lee E, Salic A, Kruger R, Heinrich R, Kirschner MW. The roles of APC and Axin derived from experimental and theoretical analysis of the Wnt pathway. PLoS Biol 2003;1(1): 116-132. 
8. Colnot S, Decaens T, Niwa-Kawakita M, Godard C, Hamard G, Kahn A, et al. Liver-targeted disruption of Apc in mice activates beta-catenin signaling and leads to hepatocellular carcinomas. Proc Natl Acad Sci U S A 2004;101(49):17216-17221.

9. Satoh S, Daigo Y, Furukawa Y, Kato T, Miwa N, Nishiwaki T, et al. AXIN1 mutations in hepatocellular carcinomas, and growth suppression in cancer cells by virus-mediated transfer of AXIN1. Nat Genet 2000;24(3):245-250.

10. Zucman-Rossi J, Benhamouche S, Godard C, Boyault S, Grimber G, Balabaud C, et al. Differential effects of inactivated Axin1 and activated beta-catenin mutations in human hepatocellular carcinomas. Oncogene 2007;26(5):774-780.

11. Boyault S, Rickman DS, de Reynies A, Balabaud C, Rebouissou S, Jeannot E, et al. Transcriptome classification of HCC is related to gene alterations and to new therapeutic targets. Hepatology 2007;45(1):42-52.

12. Feng GJ, Cotta W, Wei XQ, Poetz O, Evans R, Jarde T, et al. Conditional disruption of Axin1 leads to development of liver tumors in mice. Gastroenterology 2012;143(6):1650-1659.

13. Cadoret A, Ovejero C, Terris B, Souil E, Levy L, Lamers WH et al. New targets of b-catenin signaling in the liver are involved in the glutamine metabolism. Oncogene, 2002; 21(54):8293-301.

14. Renard CA, Labalette C, Armengol C, Cougot D, Wei Y, Cairo S et al. Tbx3 is a downstream target of the Wnt/beta-catenin pathway and a critical mediator of betacatenin survival functions in liver cancer. Cancer Res, 2007; 67(3):901-10.

15. Ovejero C, Cavard C, Perianin A, Hakvoort T, Vermeulen J, Godard C et al. Identification of the leukocyte cell-derived chemotaxin 2 as a direct target gene of beta-catenin in the liver. Hepatology 2004; 40(1): 167-76. 
16. Benhamouche S, Decaens T, Godard C, Chambery R, Rickman DS, Moinard C. Apc tumor suppressor gene is the "zonation-keeper" of mouse liver. Dev Cell 2006; 10(6):759-70.

17. Wang J, Park JS, Wei Y, Rajurkar M, Cotton JL, Fan Q et al. TRIB2 acts downstream of Wnt/TCF in liver cancer cells to regulate YAP and C/EBPa function. Mol Cell 2013; 51(2):211-25.

18. Pilati C, Letouzé E, Nault JC, Imbeaud S, Boulai A, Calderaro J. Genomic profiling of hepatocellular adenomas reveals recurrent FRK-activating mutations and the mechanisms of malignant transformation. Cancer Cell 2014; 25(4): 428-41.

19. Guichard C, Amaddeo G, Imbeaud S, Ladeiro Y, Pelletier L, Maad IB et al. Integrated analysis of somatic mutations and focal copy-number changes identifies key genes and pathways in hepatocellular carcinoma. Nat Genet. 2012; 44(6): 694-8. 20. Audard V, Grimber G, Elie C, Radenin B, Audebourg A, Letourneur F et al. Cholestasis is a marker for hepatocellular carcinomas displaying beta-catenin mutations. J Pathol 2007; 212(3):345-52.

21. Hoshida Y, Nijman SM, Kobayashi M, Chan JA, Brunet JP, Chiang DY, et al. Integrative transcriptome analysis reveals common molecular subclasses of human hepatocellular carcinoma. Cancer Res 2009;69(18):7385-7392.

22. Chiang DY, Villanueva A, Hoshida Y, Peix J, Newell P, Minguez B, et al. Focal gains of VEGFA and molecular classification of hepatocellular carcinoma. Cancer Res 2008 ;68(16):6779-6788.

23. Zhang H, Yao M, Wu W, Qiu L, Sai W, Yang J, et al. Up-regulation of annexin A2 expression predicates advanced clinicopathological features and poor prognosis in hepatocellular carcinoma. Tumour Biol 2015;36(12):9373-9383. 
24. Schmitz KJ, Wohlschlaeger J, Lang H, Sotiropoulos GC, Malago M, Steveling $\mathrm{K}$, et al. Activation of the ERK and AKT signalling pathway predicts poor prognosis in hepatocellular carcinoma and ERK activation in cancer tissue is associated with hepatitis C virus infection. J Hepatol 2008 ;48(1):83-90.

25. Hayward P, Balayo T, Martinez Arias A. Notch synergizes with axin to regulate the activity of armadillo in Drosophila. Dev Dyn 2006;235(10):2656-2666.

26. Munoz-Descalzo S, Tkocz K, Balayo T, Arias AM. Modulation of the ligandindependent traffic of Notch by Axin and Apc contributes to the activation of Armadillo in Drosophila. Development 2011;138(8):1501-1506.

27. Azzolin L, Panciera T, Soligo S, Enzo E, Bicciato S, Dupont S, et al. YAP/TAZ incorporation in the beta-catenin destruction complex orchestrates the Wnt response. Cell $2014 ; 158(1): 157-170$.

28. Liu W, Rui H, Wang J, Lin S, He Y, Chen M, et al. Axin is a scaffold protein in TGF-beta signaling that promotes degradation of Smad7 by Arkadia. Embo J 2006 ;25(8):1646-1658.

29. Rui Y, Xu Z, Xiong B, Cao Y, Lin S, Zhang M, et al. A beta-cateninindependent dorsalization pathway activated by Axin/JNK signaling and antagonized by aida. Dev Cell 2007;13(2):268-282.

30. Villanueva A, Alsinet C, Yanger K, Hoshida Y, Zong Y, Toffanin S, et al. Notch signaling is activated in human hepatocellular carcinoma and induces tumor formation in mice. Gastroenterology 2012;143(6):1660-1669.

31. Sulpice L, Rayar M, Desille M, Turlin B, Fautrel A, Boucher E, et al. Molecular profiling of stroma identifies osteopontin as an independent predictor of poor prognosis in intrahepatic cholangiocarcinoma. Hepatology 2013;58(6):1992-2000. 
32. Cordenonsi M, Zanconato F, Azzolin L, Forcato M, Rosato A, Frasson C, et al. The Hippo transducer TAZ confers cancer stem cell-related traits on breast cancer cells. Cell 2011;147(4):759-772.

33. Dai Y, Liu L, Zeng T, Zhu YH, Li J, Chen L et al. Characterization of the oncogenic function of centromere protein $\mathrm{F}$ in hepatocellular carcinoma. Biochem Biophys Res Commun. 2013 Jul 12;436(4):711-8.

34. Li G, Zhong Y, Shen Q, Zhou Y, Deng X, Li C et al. NEK2 serves as a prognostic biomarker for hepatocellular carcinoma. Int J Oncol. 2017 50(2):405-413.

35. Wang WM, Xu Y, Wang YH, Sun HX, Sun YF, He YF et al. HoxB7 promotes tumor progression via bFGF-induced activation of MAPK/ERK pathway and indicated poor prognosis in hepatocellular carcinoma. Oncotarget 2017; 8(29):47121-47135.

36. Monga SP. beta-Catenin Signaling and Roles in Liver Homeostasis, Injury, and Tumorigenesis. Gastroenterology 2015;148(7):1294-1310.

37. Lachenmayer A, Alsinet C, Savic R, Cabellos L, Toffanin S, Hoshida Y, et al. Wnt-pathway activation in two molecular classes of hepatocellular carcinoma and experimental modulation by sorafenib. Clin Cancer Res 2012;18(18):4997-5007.

38. Tschaharganeh DF, Chen X, Latzko P, Malz M, Gaida MM, Felix K, et al. Yesassociated protein up-regulates Jagged-1 and activates the Notch pathway in human hepatocellular carcinoma. Gastroenterology 2013;144(7):1530-1542.

39. Leung CO, Mak WN, Kai AK, Chan KS, Lee TK, Ng IO, et al. Sox9 confers stemness properties in hepatocellular carcinoma through Frizzled-7 mediated Wnt/beta-catenin signaling. Oncotarget 2016; 29371-29386.

40. Cao L, Fan X, Jing W, Liang Y, Chen R, Liu Y, et al. Osteopontin promotes a cancer stem cell-like phenotype in hepatocellular carcinoma cells via an integrin-NFkappaB-HIF-1alpha pathway. Oncotarget 2015;6(9):6627-6640. 
41. Kim W, Khan SK, Gvozdenovic-Jeremic J, Kim Y, Dahlman J, Kim H et al. Hippo signaling interactions with Wnt/ $\beta$-catenin and Notch signaling repress liver tumorigenesis. J Clin Invest 2017; 127 (1): 137-152.

42. Tolg C, Hamilton SR, Morningstar L, Zhang J, Zhang S, Esguerra KV, et al. RHAMM promotes interphase microtubule instability and mitotic spindle integrity through MEK1/ERK1/2 activity. J Biol Chem 2010;285(34):26461-26474.

43. Wang D, Narula N, Azzopardi S, Smith RS, Nasar A, Altorki NK, et al. Expression of the receptor for hyaluronic acid mediated motility (RHAMM) is associated with poor prognosis and metastasis in non-small cell lung carcinoma. Oncotarget $2016 ; 7(26): 39957-39969$.

44. Liu-Chittehnden Y, Huang B, Shim JS, Chen Q, Lee SJ, Anders RA et al. Genetic and pharmacological disruption of the TEAD-YAP complex suppresses the oncogenic activity of YAP. Genes and Dev 2012; 26: 1300-1305. 


\section{Figure Legends}

Figure 1. Different $\beta$-catenin activities in CTNNB1-and AXIN1-mutated HCC (A-B) Non supervised hierarchical clustering for two publicly available data sets: (A) GSE62232 (B) TGCA-LIHC. The hierarchical clustering was performed using the Euclidean distance and average linkage arrangement for both axes and shows the signature for genes involved in the canonical Wnt/ $\beta$-catenin signaling (purple) and their positively (dark yellow) and negatively (dark green) regulated liver specific target genes. Gene expression data were normalized using the z-score transformation. $A P C, A X I N 1$ and CTNNB1 mutations are indicated by red, blue and pink marks respectively. Asterix sign above APC mutations indicates $\mathrm{LOH}$. Strong, weak, and no $W n t / \beta$-catenin signaling clusters are indicated. Levels of expression are indicated for APC and AXIN1 mutation: -2 (dark green) indicates a deep loss and possible homozygous deletion, -1 (light green) indicates a shallow loss and possible heterozygous deletion, 0 (white) indicates diploid, 1 (light red) indicates a low-level gain, and 2 (dark red) indicates a high-level amplification.

(C) Stacked bar chart showing the distribution of CTNNB1 and AXIN1 mutations in the three defined levels of $\beta$-catenin program activation: strong, weak or no activation.

Figure 2. Generation of Axin $1^{f / f / f}$ mice. (A) Schematic representation of the wild-type (WT) and mutated Axin1 alleles, with the localization of binding sites for Apc, $\beta$ catenin and GSK3 $\beta$. LoxP sequences are indicated by black triangles and FRT sites by gray rectangles. FLP recombinase was used to delete the hygromycin selection gene in ES cells. (B) Southern blot of WT and heterozygous wt/fl ES cells before the use of FLP recombinase. (C) Immunodetection of Axin1 in the liver of monogenic 
Axin $1^{\text {fl/fl }}$ mice (WT) and double-transgenic KO LivEmb or KO LivAd, 15 days after the injection of tamoxifen. Gapdh was used as a loading control.

Figure 3. Absence of activaction of the Wnt/ $\beta$-catenin pathway in HCC developing in KO LivEmb and KO LivAd mice. (A) upper panel: macroscopic appearance of representative livers from KO LivEmb and KO LivAd mice at 12-14 months. Arrowheads indicate tumors; lower panel: Representative HE-stained sections showing tumors with steatosis (100x). (B) Immunostaining for $\beta$-catenin (CTNNB1) expression and glutamine synthase (GS) (200x). (C) RT-qPCR analysis of target genes upregulated by $\beta$-catenin, in the tumors of KO LivAd mice (T) and in non-tumor samples from the same mice (NT) at 9 to 14 months after tamoxifen injection $(n=6$ male mice). Data are presented as the mean + SEM, with a comparison between tumor (T) and non-tumor (NT) samples. Comparisons between two groups were performed with two-tailed unpaired $t$ test showed no significant difference. (D) Immunoblot analysis of Axin2 levels in the liver of monogenic control Axin $1^{\mathrm{fl} / \mathrm{fl}}$ mice (WT) and KO LivEmb mice. Gapdh is used as a loading control.

Figure 4. Absence of activation of the Wnt/ $\beta$-catenin signalling in pretumoral livers displaying Axin1 deletion. (A) Liver sections immuno-stained for GS (100x except for the APC KO, 200x) and $\beta$-catenin $(200 x)$ in monogenic control mice (WT), KO LivEmb mice with Axin1 deletion at the age of four months, KO LivAd mice four months after tamoxifen injection and APC KO mice after Apc deletion. (B) RT-qPCR analysis of target genes upregulated by $\beta$-catenin, in the livers of WT $(n=6)$, KO LivEmb ( $n=3$ females and 3 males), KO LivAd ( $n=6$ male) mice and mice with Apc deletion (APC KO $n=3$ ). Data are presented as the mean + SEM, with comparisons 
to WT mice. Only APC KO livers displayed significant gene induction relative to WT livers using unpaired t test $\left({ }^{* * *} p<0.001\right)$.

Figure 5. Tumors with Axin1 deletion recapitulate the characteristics of human HCCs subgroups with no CTNNB1 mutations and features associated with a poor prognosis.

(A) GSEA revealing significant enrichment in various human oncogenic gene signatures. NES: Normalized Enrichment Score for GSEA algorithm. (B) Relative expression, as assessed by RT-qPCR, of fetal genes in tumors with Axin1 deletion (T) $(n=7)$ and the corresponding non-tumor (NT) samples $(n=7)$ from KO LivAd male livers. Data are presented as the mean + SEM, with comparison to the corresponding NT samples $\left({ }^{* *} p<0.01,{ }^{* * *} p<0.001\right)$. Comparisons between two groups were performed with two-tailed unpaired $t$ test. (C) Immunoblot analysis of control Axin $1^{\mathrm{fl} / \mathrm{fl}}$ Cre- mouse livers (WT), tumors (T) corresponding non-tumor (NT) samples for Anxa2, ERK and p-ERK. $\gamma$-tubulin was used as a loading control.

Figure 6. Notch and Yap oncogenic pathways are activated in HCC with Axin1 deletion

(A) GSEA showed that the gene expression profiles of tumors with Axin1 deletions (T) and adjacent non-tumor tissues (NT) were significantly enriched in gene signatures corresponding to genes up- and downregulated, respectively, in NICDinduced tumors (28). (B) Relative RNA levels, as determined by RT-qPCR, for Notch pathway target genes in tumors with Axin1 deletion (T) $(n=7)$ and in non-tumor tissues (NT) (n=9) from KO LivAd male mouse livers. (C) Western-blot analysis of liver tumors with Axin1 deletion (T) and adjacent non-tumor (NT) samples for osteopontin in KO LivEmb mice and KO LivAd mice. $\left({ }^{*} p<0.05\right.$, ${ }^{* *} p<0.01$, 
${ }^{* * *} p<0.001$ ) (D) Sections from a KO LivEmb liver tumor $(T)$ and the corresponding non-tumor sample (NT), immunostained for Sox9. Note the intense nuclear staining in the tumor sample. (E) GSEA demonstrating specific enrichment for a Yap oncogenic signature in the gene expression profile of tumors with Axin1 deletion. (F) RT-qPCR analysis of target genes upregulated by Yap, in T $(n=7)$ and NT $(n=9)$ samples from KO LivAd livers. (G) Immunoblot analysis of Yap/Taz levels in T and NT samples from livers with Axin1 deletion from KO LivEmb mice. * $p<0.05$, ** $p<0.01,{ }^{* * *} p<0.001$. Comparisons between two groups were performed with twotailed unpaired $t$ test.

Nuclear extracts (Nuc) from 2 KO LivEmb tumors $(\mathrm{T})$ and their adjacent non tumoral counterpart (NT) confirmed an enrichment of YAP/ TAZ in tumoral nuclei. P84 was used as a loading control for nuclear proteins.

Figure 7. Notch and YAP enriched signature in AXIN1-mutated HCC

(A) Venn diagram showing the overlap of the 329-gene AXIN1 signature with the 384-gene $\mathrm{NOTCH}$-induced tumoral signature described by Villanueva et al (28) and the YAP/TAZ tumoral signature described by Cordenonsi et al (30). Exact Fisher test used all 20530 genes tested in the TGA-LIHC as reference gene set with a $p$ value $<0.0001$.

(B) Non supervised hierarchical cluster for the merged Human TGCA-LIHC and Mouse Affymetrix data set. The human and mouse dataset were normalized separately and z-Score transformed respectively, before they were merged together. The hierarchical cluster was performed using the Pearson distance and average linkage arrangement for both axes and shows the 54 Notch pathway genes overlapping with the 329 gene AXIN1 signature. On the right side are shown the Notch signature genes up or down regulated in AXIN1 mutated/deleted tumors vs. 
normal liver tissue. AXIN1 mutated or deleted tumors are in represented in blue, in cyan non-tumor mouse liver tissue deleted for AXIN1 and in orange normal distant liver tissue for human and mouse. 
A
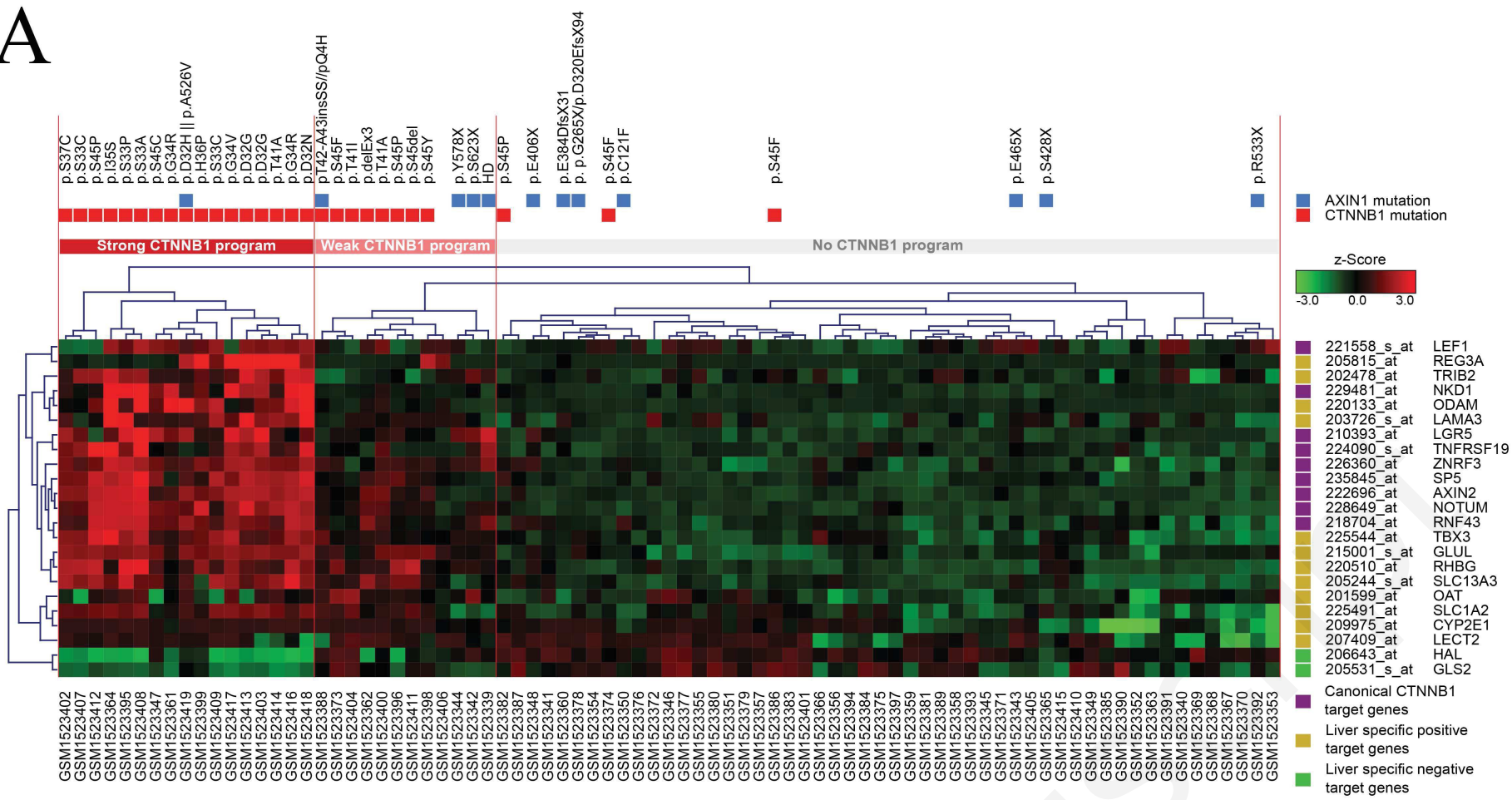

B

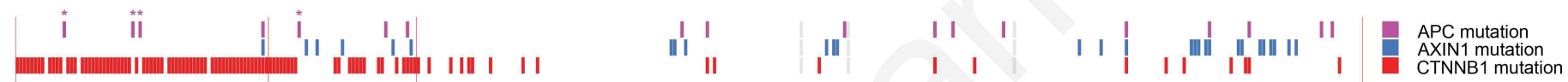

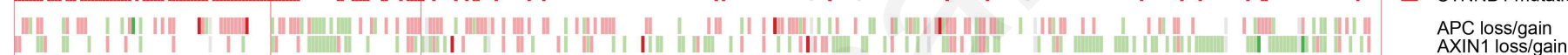
Strong CTNNB1 program Weak CTNNBi program

No CTNNB1 program

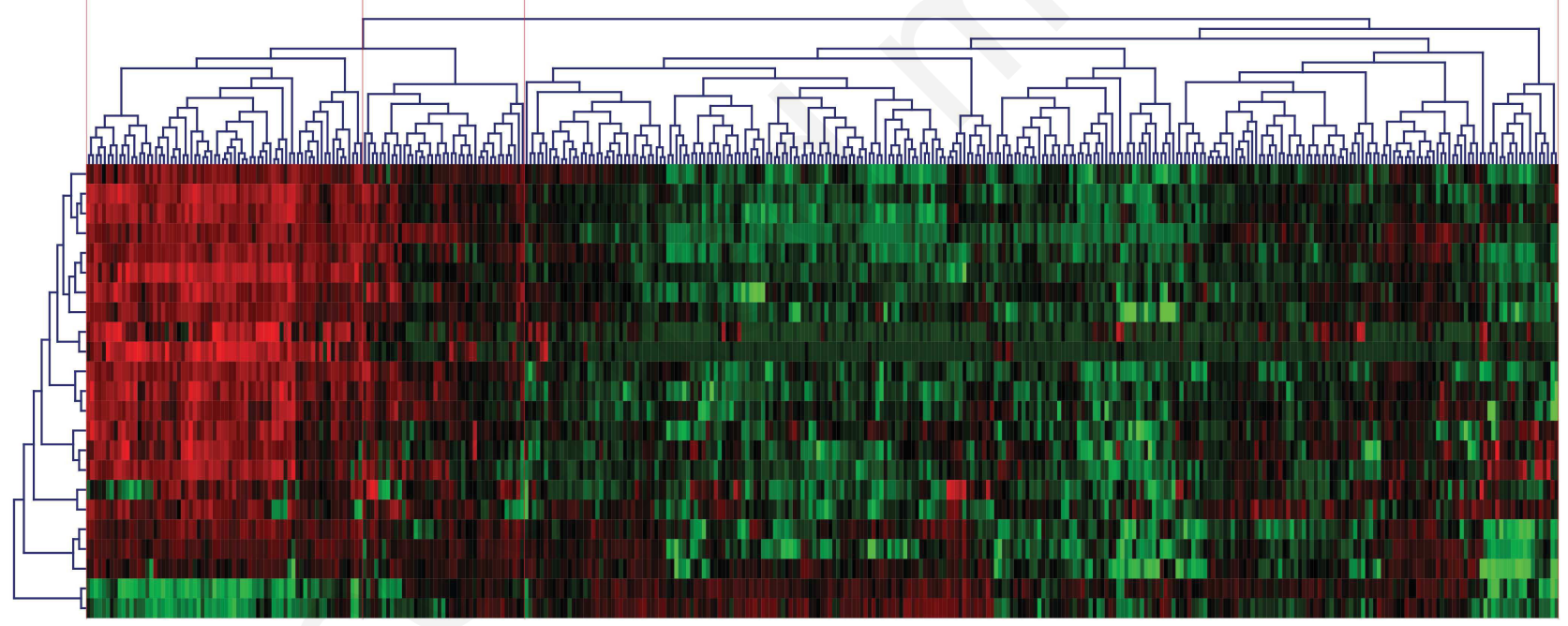

loss / gain

\begin{tabular}{l}
\hline$-2.0-1.00 .01 .02 .0$ \\
Z-Score \\
\hline$-3.0 \quad 0.0 \quad 3.0$ \\
SLC13A3 \\
NKD1 \\
AXIN2 \\
LGR5 \\
RHBG \\
GLUL \\
SSP5 \\
TBX3 \\
REG3A \\
ODAM \\
NOTUM \\
ZNRF3 \\
RNF43 \\
LAMA3 \\
TRIB2 \\
TNFRSF19 \\
OAT \\
LEF1 \\
SLL1A2 \\
CYP21 1 \\
LECT2 \\
HAL \\
GLS2 \\
Canonical CTNNB1 \\
target genes \\
Liver specific positive \\
target genes \\
Liver specific negative \\
target genes \\
Data Not Available
\end{tabular}
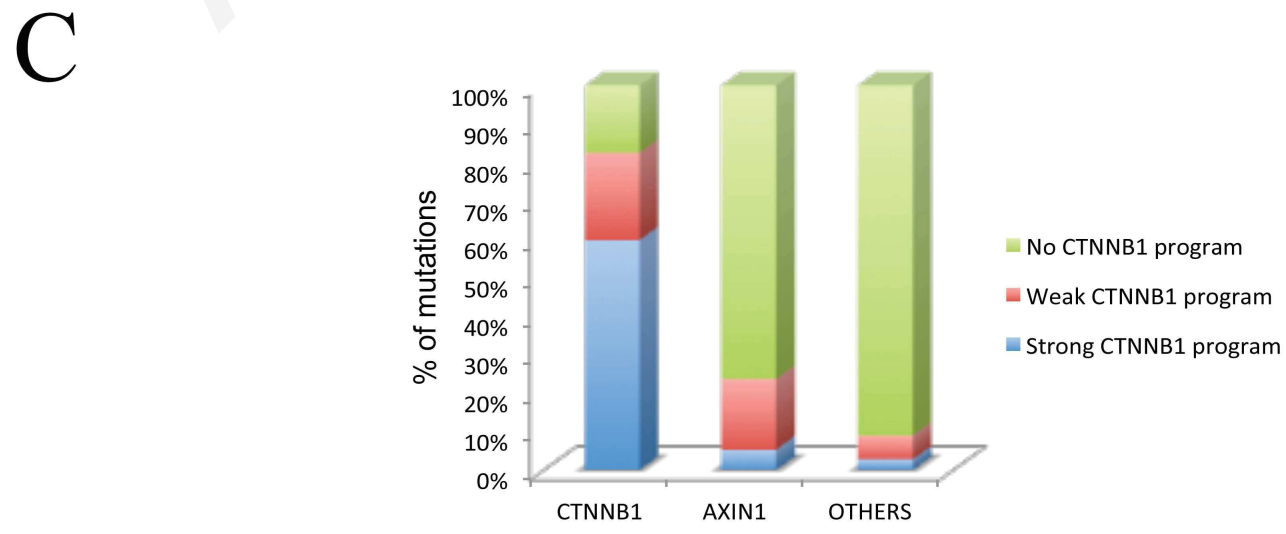


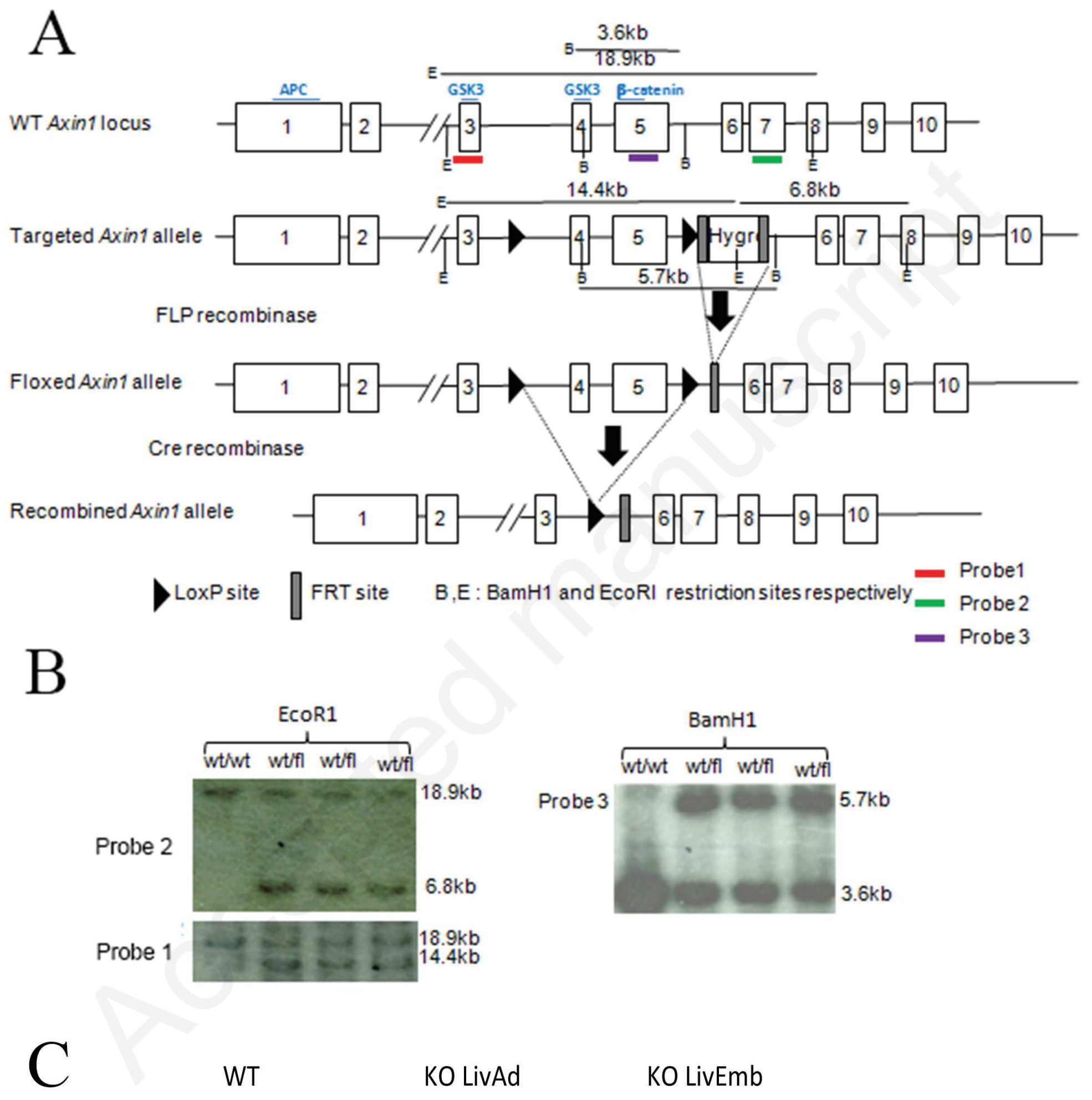

Axin1

GAPDH 
A
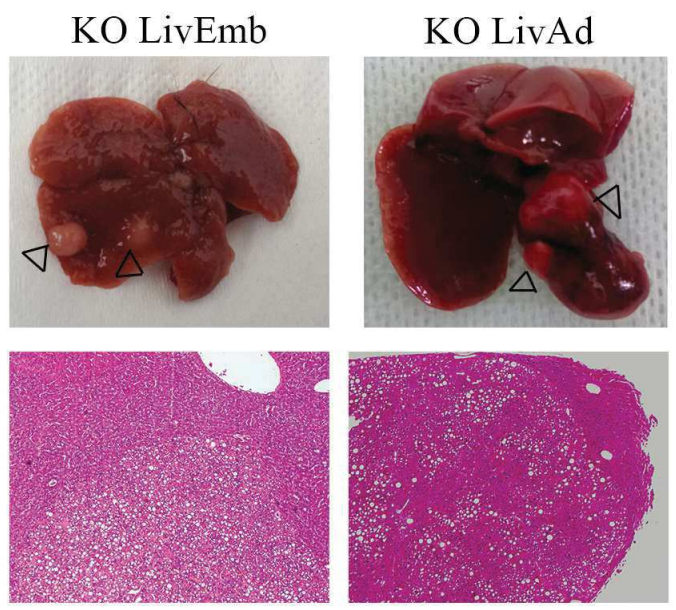

C

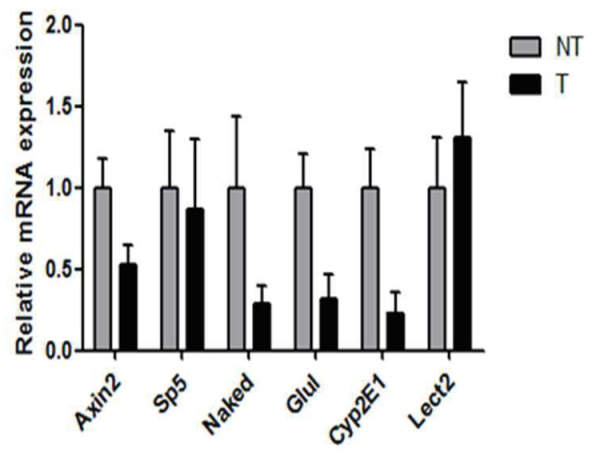

B
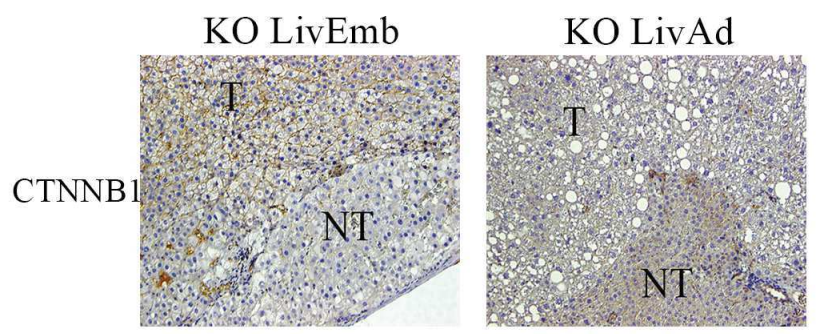

GS
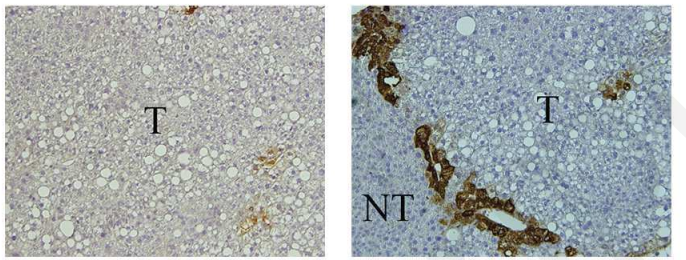

D

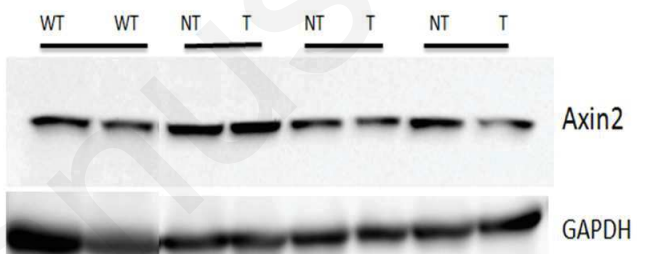


Figure 4

A

B

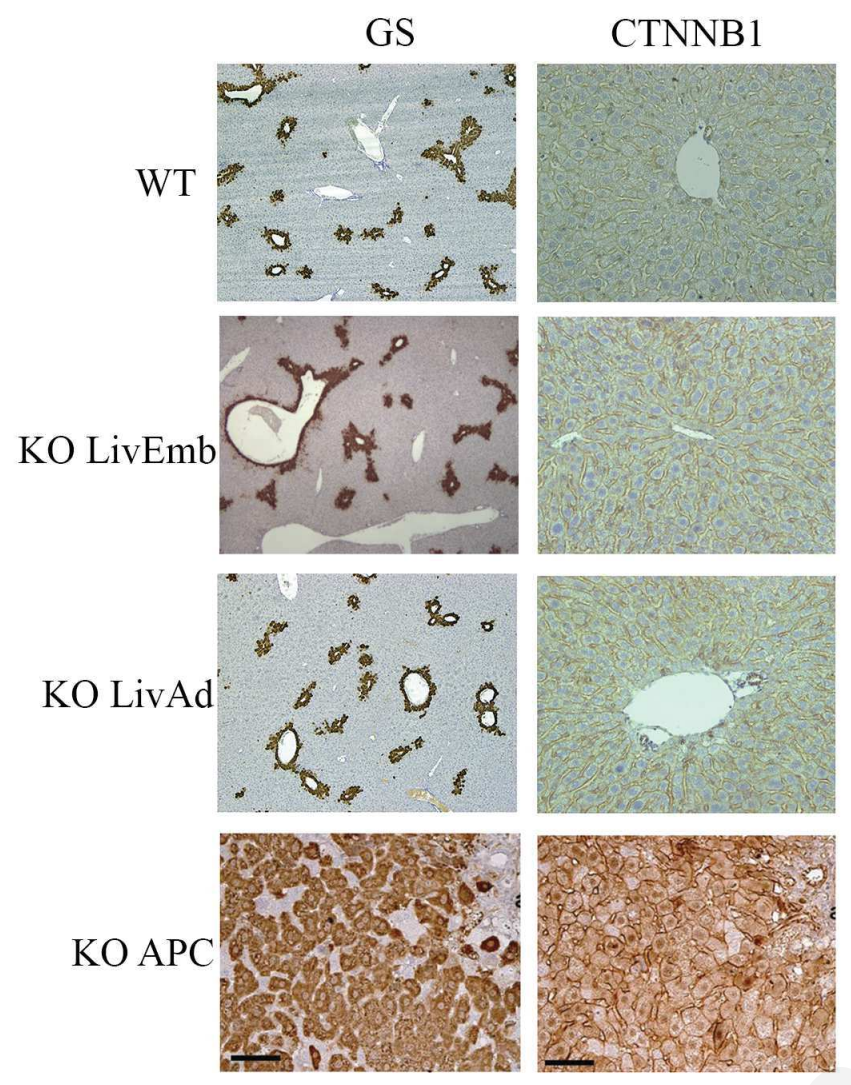


Figure 5

A

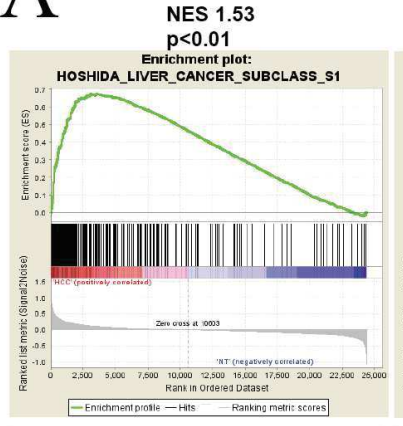

Enrichment plot: WANG_TUMOR_INVASIVENESS_UP
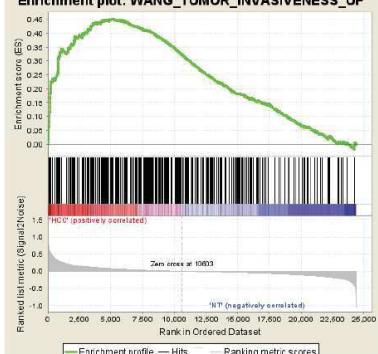
NES 1.83

$\mathrm{p}<0.01$
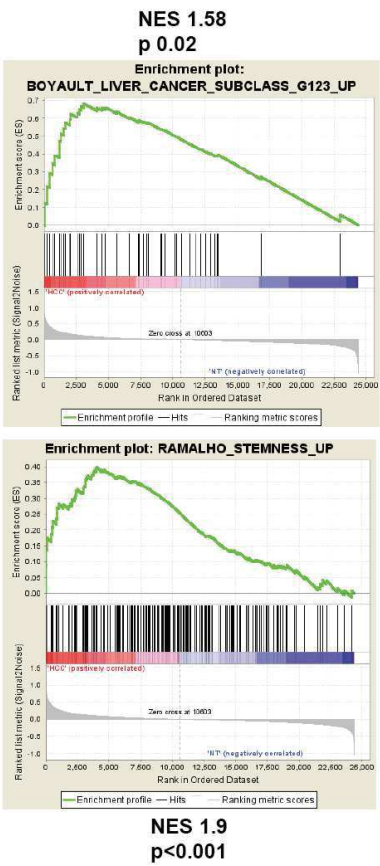

Enrichment plot:
CHIANG_LIVER_CANCER_SUBCLASS_PROLIFERATION_U

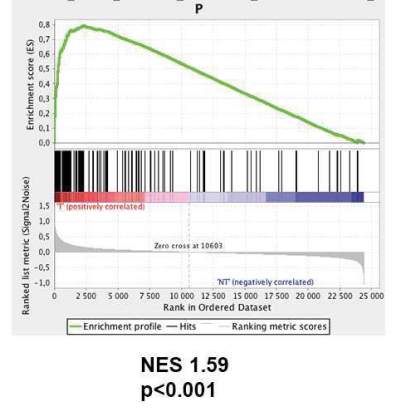

B

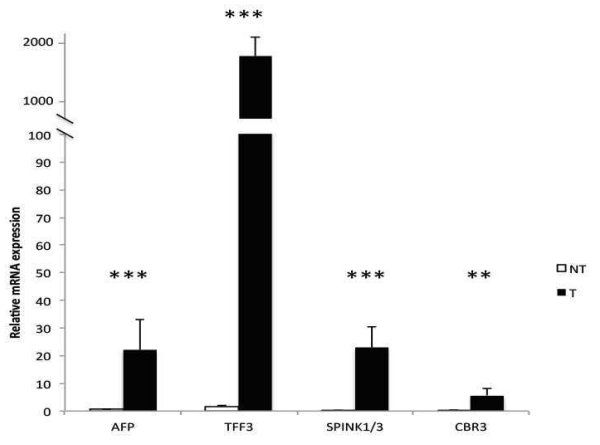

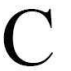

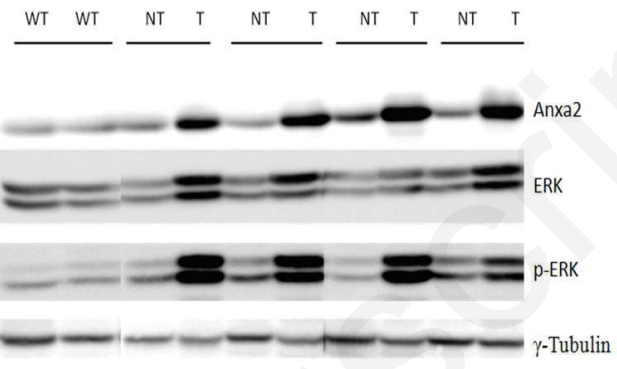


A

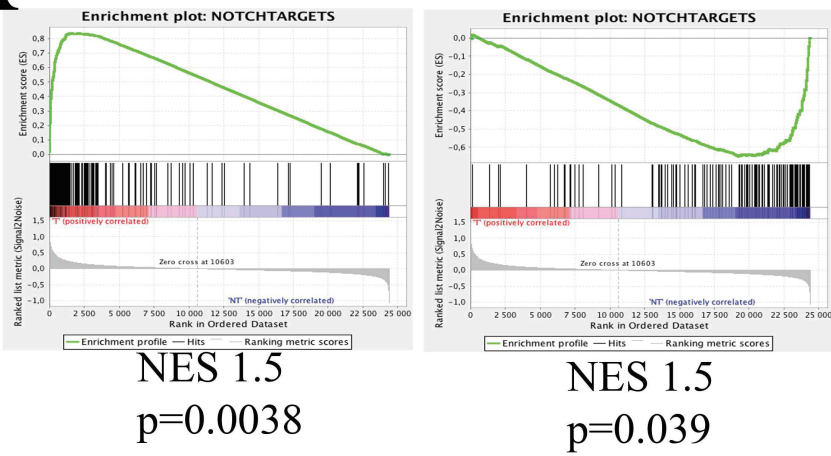

C

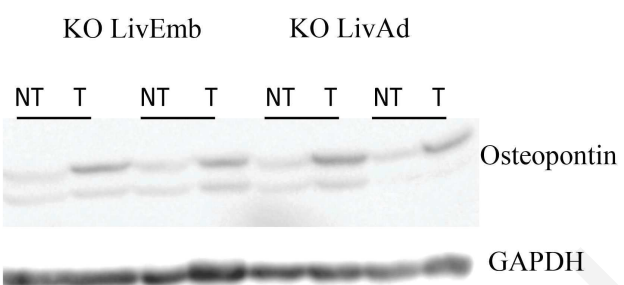

E

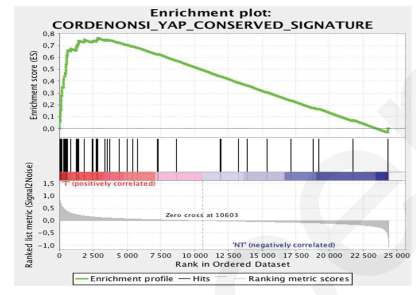

NES 1.48

$\mathrm{p}<0.05$

G

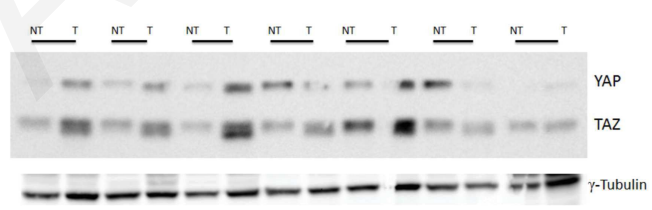

B
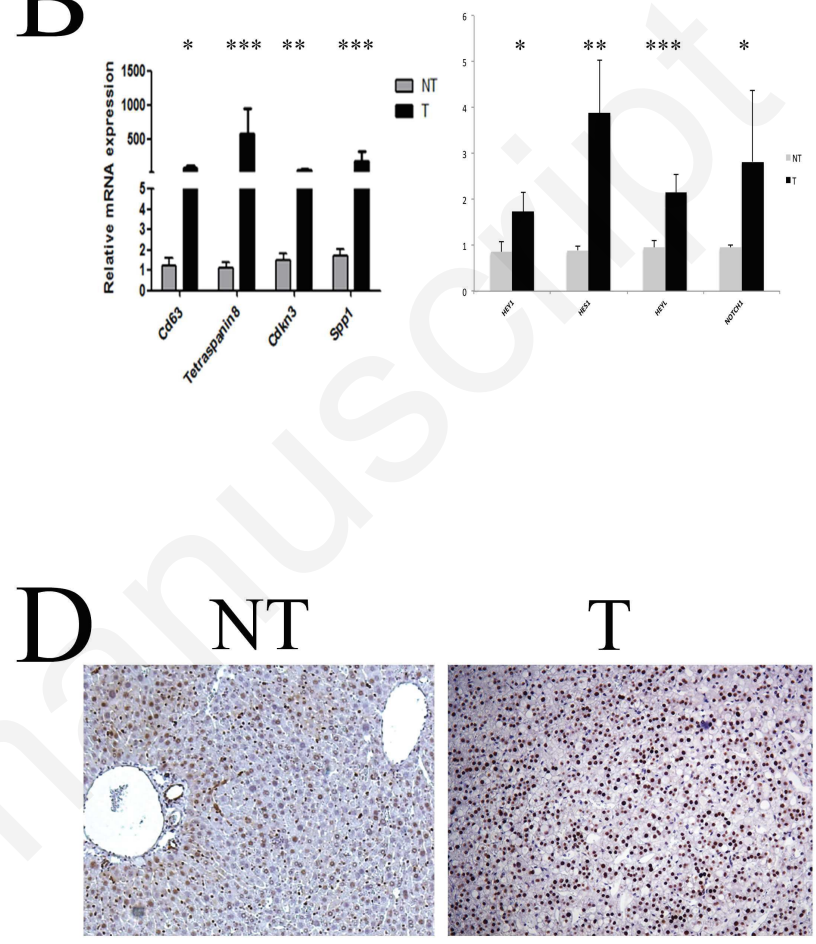

F
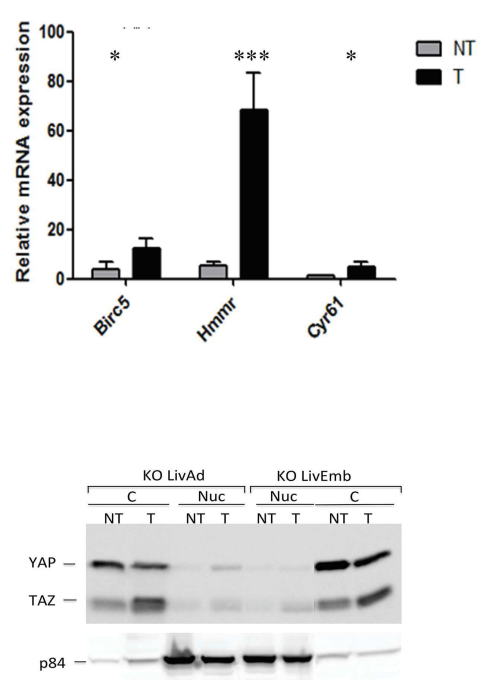
A

\section{9-gene signature 384-gene signature}

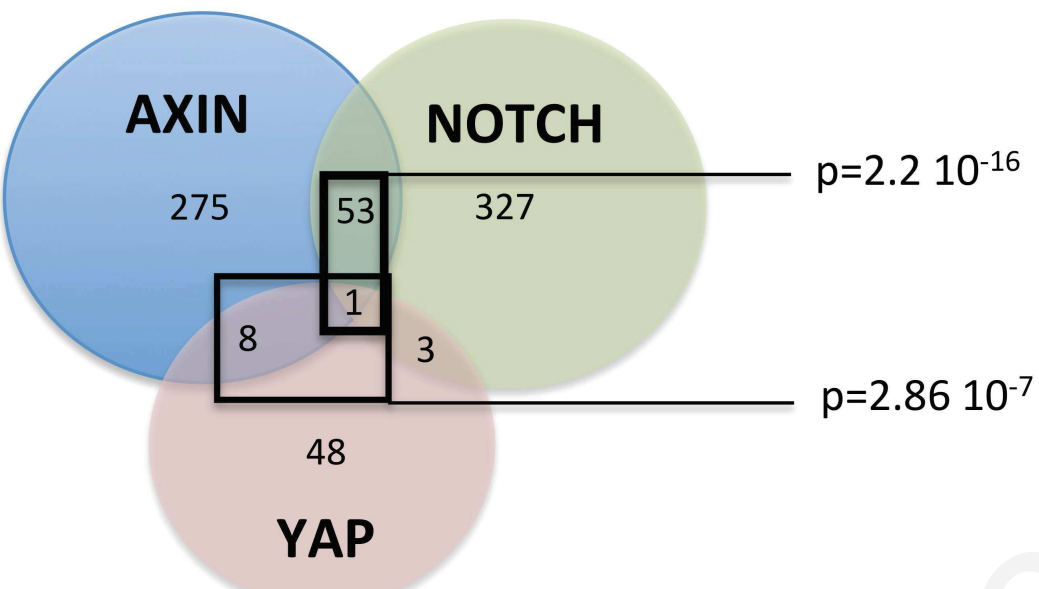

57-gene signature

B

r $\begin{array}{ll} & \\ 9 & 1\end{array}$

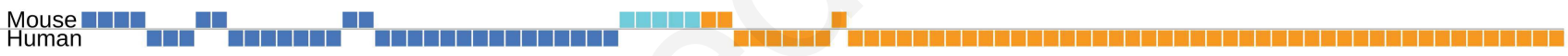
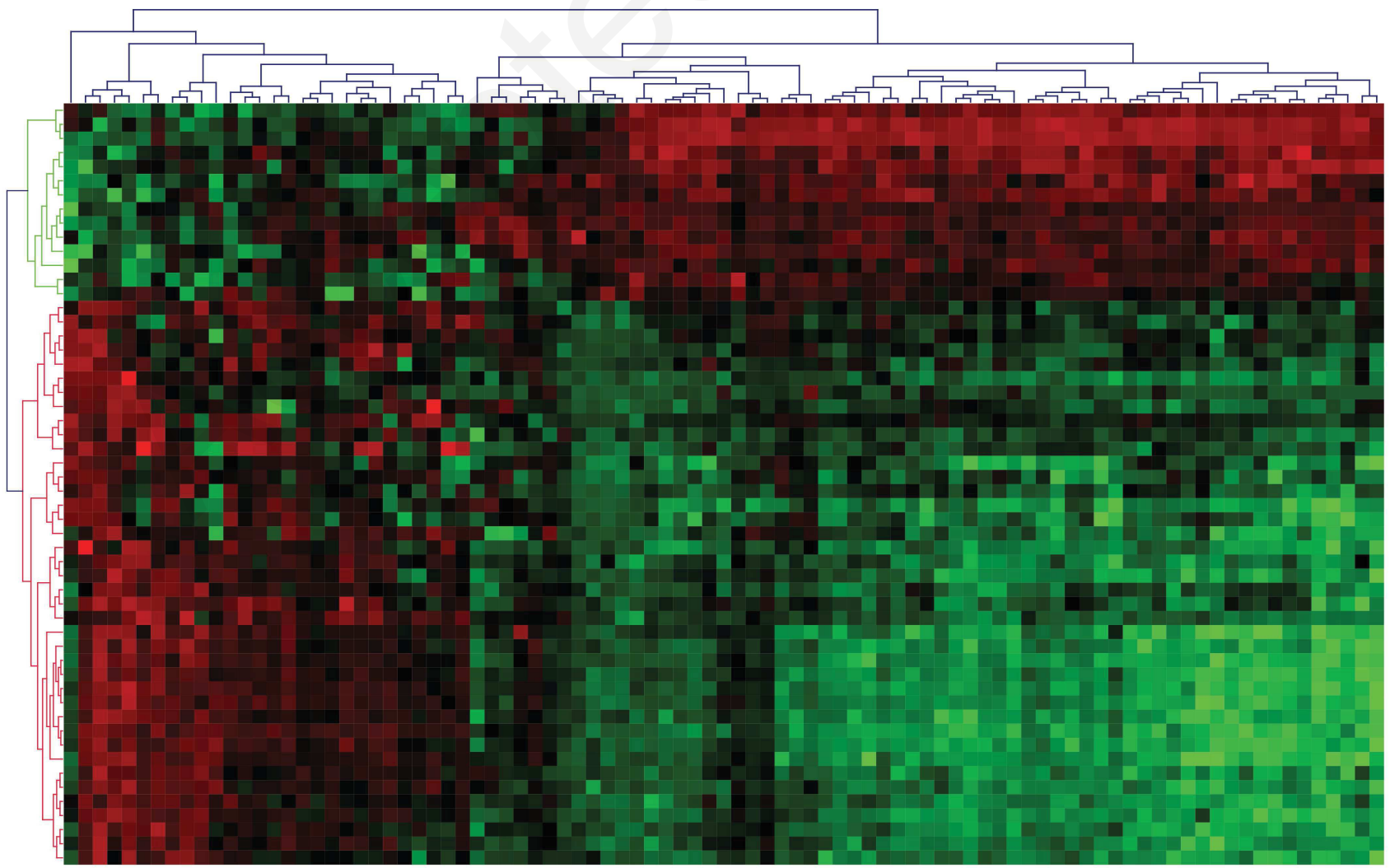

z-Score

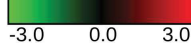

AXIN1 mutation AXIN1 mutation - Normal Liver

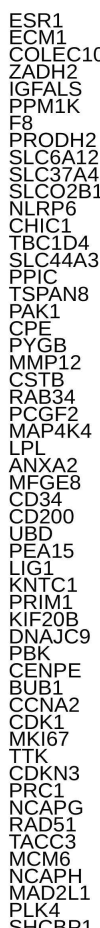




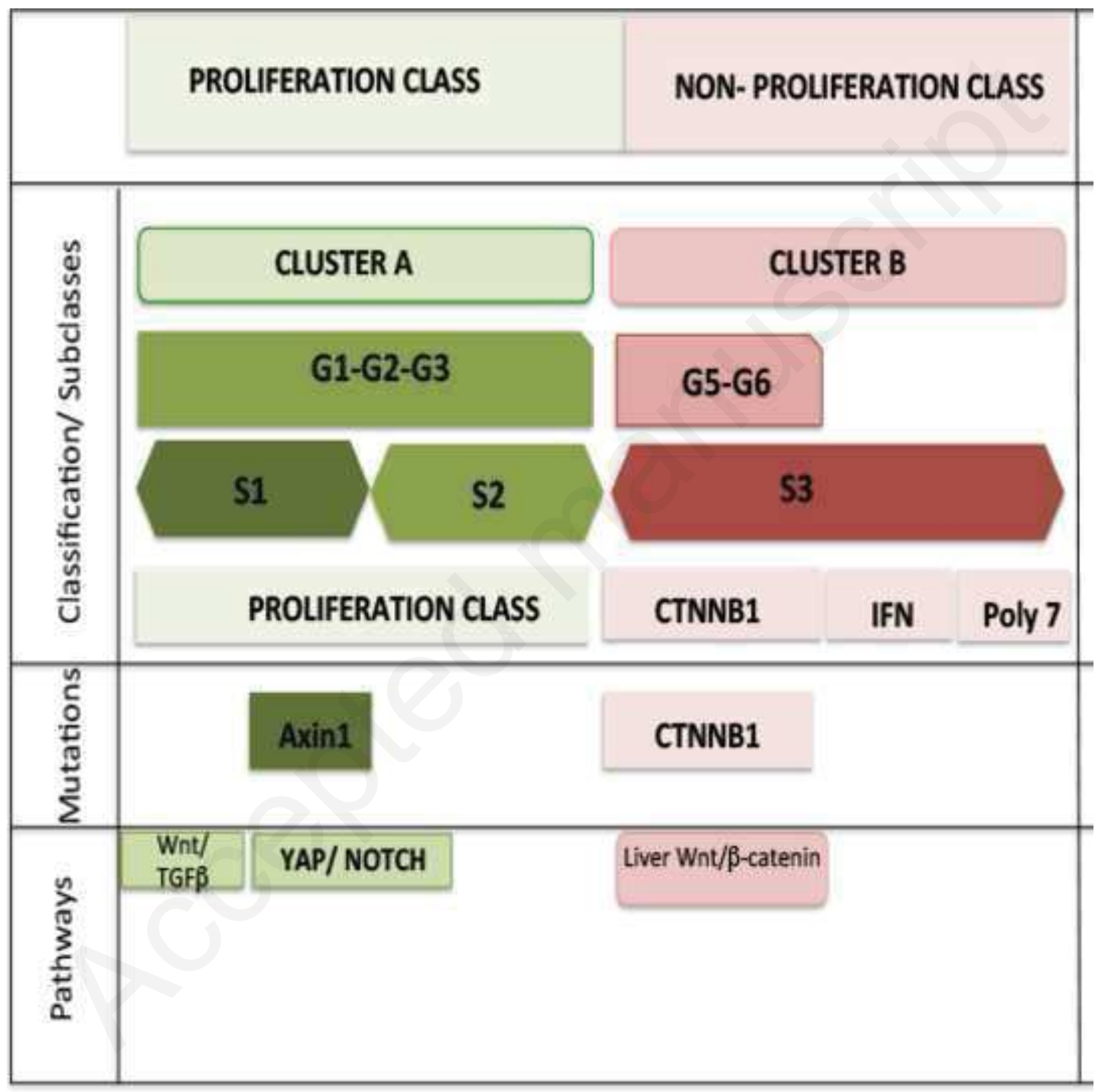




\section{Highlights:}

- Most human AXIN1 mutated hepatocellular carcinomas do not show a $\beta$-catenin activation program

${ }^{\circ} \mathrm{HCC}$ induced by Axin 1 deficiency in mice develop independently of $\mathrm{Wnt} / \beta$-catenin pathway activation

- The tumor signature is enriched in genes associated with invasion stemness and poor prognosis.

- The 329 common genes signature of mouse and human AXIN1 mutated HCC is highly enriched in Notch and YAP pathways 